www.jmscr.igmpublication.org

Impact Factor (SJIF): 6.379

Index Copernicus Value: 71.58

ISSN (e)-2347-176x ISSN (p) 2455-0450

crossrefDOI: https://dx.doi.org/10.18535/jmscr/v6i7.69

Journal Of Medical Science And Clinical Research

\title{
A cross sectional study to find out the awareness and use of E-learning methods among medical students of a cosmopolitan city of central India
}

\author{
Authors \\ Dr Anand Kumar Patidar ${ }^{1}$, Dr Deepa Raghunath ${ }^{2 *}$, Dr Harish Shukla, Dr Sanjay Dixit ${ }^{3}$ \\ Krati Jain, Krishna Patel, Meena Singrol, Minaxi Dudwe, Mohsin Nagori \\ ${ }^{1}$ Resident, ${ }^{2}$ Associate Professor, ${ }^{3}$ Prof. \& HOD of Community Medicine \\ MGM Medical College Indore Madhya Pradesh, India \\ *Corresponding Author \\ Dr Deepa Raghunath
}

\begin{abstract}
Background: E -learning is defined as acquisition of knowledge and skill using electronic technologies such as computer and Internet based courseware and local and wide area networks. E-learning encompasses a pedagogical approach that typically aspires to be flexible, engaging and learner-centred. Methods: It is a cross sectional study done in 3 months of study period (September 2016-December 2016) in government medical college of Indore city. 150 medical students between age group 18-25 years were selected by simple random sampling method for data collection. Pre-designed, semistructured questionnaire which assess the awareness regarding e-learning were used.

Results: $100 \%$ study population were aware of methods of e-learning. Most of the study population preferred chalk and board (66.7\%) and power point presentation (27\%) while dictation and transparency were less preferred method for learning. 55.4\% study population felt that e-learning helps in increasing their interest and helps in building their concept toward the topic (57\%).

Conclusion: Nearly half of the study population feel that e-learning helps in increasing their interest towards the topic. It helps to increased access to information and ease in sharing of information.
\end{abstract}

Keywords: Awareness, e-learning, medical students.

\section{Introduction}

E -learning is defined as acquisition of knowledge and skill using electronic technologies such as computer and Internet based courseware and local and wide area networks ${ }^{(1)}$. Typically used to describe media such as CD-ROM, Internet, Intranet, wireless and mobile learning. The term was introduced in 1995 when it was all called "Internet based Training", then "Web-based Training" (to clarify that delivery could be on the Inter- or Intra-net), then "Online Learning" and finally e-learning, adopting the in vogue use of "e" during the dot com boom ${ }^{(2)}$. E-learning can be used by medical educators to improve the efficiency and effectiveness of educational interventions in the face of the social, scientific, and pedagogical challenges noted above. It has gained popularity in the past decade; however, its use is highly variable among medical schools and appears to be more common in basic science courses than in clinical clerkships ${ }^{(3,4)}$. 


\section{Types of E-learning}

There have been two common e-learning modes: distance learning and computer assisted instruction. Distance learning uses information technologies to deliver from a central site, instruction to learners who are at remote locations. Computer-assisted instruction (CAL) uses computers to aid in the delivery of stand-alone multimedia packages for learning and teaching ${ }^{(5)}$. In the process of learning the teacher aims at providing knowledge to the taught through various means and methods. The system is called traditional method of learning but the present education system aims at providing the teacher and the learner to be a literate of technology. Technology improves the quality of education by facilitating learning by doing, real time conversation, delayed time conversation, directed instruction, self-learning, problem solving, information seeking and analysis, and critical thinking, as well as the ability to communicate, collaborate and learn ${ }^{(6)}$. E-learning encompasses a pedagogical approach that typically aspires to be flexible, engaging and learner-centred; one that encourages interaction and collaboration and communication, often synchronously or asynchronously $^{(7)}$. E-learning is electronic learning, and typically this means using a computer to deliver part, or all of a course whether it's in a school, college, part of training or a full distance learning course ${ }^{(8)}$.

\section{Aims \& Objectives}

(1) To assess the awareness about the methods of E-learning. (2) To find out advantages and disadvantages of E-learnings as felt by study population.

\section{Methodology}

It is a cross sectional study done in 3 months of study period (September 2016-December 2016) in government medical college of Indore city. 150 medical students between age group 18-25 years were selected by simple random sampling method for data collection. Pre-designed, semi-structured questionnaire which assess the awareness regarding e-learning were used. Students not within the defined age group and not given consent for being part of study were excluded. Written consent was taken from each students prior to filling the questionnaire. Data collected and entered in Microsoft Excel sheet. Data were analysed using SPSS software version 20 using appropriate statistical tests like frequencies and chi square tests.

\section{Results}

This study revealed that the mean age of the study population was 21.7 years with standard deviation of 2.13 .

Table 1- Table showing demographic distribution of the study population

\begin{tabular}{|l|c|c|}
\hline Demographic profile & Options & No. of Participants(150) \\
\hline Age of Participants & $18-19$ years & $26(17.3 \%)$ \\
& $20-21$ years & $50(33.3 \%)$ \\
& $22-23$ years & $38(25.4 \%)$ \\
\hline Gender & $24-25$ years & $36(24 \%)$ \\
\hline Region of schooling & Male & $98(65.3 \%)$ \\
& Female & $52((34.7 \%)$ \\
\hline Medium of education during schooling period & Rural & $50(33.3 \%)$ \\
& Urban & $100(66.7 \%)$ \\
\hline
\end{tabular}

In our study $100 \%$ study population were aware of methods of e-learning. Most of the study population had urban region of schooling and their medium of education during school period was English. 
Table 2 Table showing modes of learning preferred and ability to use computer and internet among the study population

\begin{tabular}{|l|c|c|}
\hline Questions & Options & $\begin{array}{c}\text { No. of } \\
\text { Participants(150) }\end{array}$ \\
\hline $\begin{array}{l}\text { Modes of class based learning } \\
\text { preferred by study population }\end{array}$ & (1) Chalk and Board & $100(66.7 \%)$ \\
& (2) Dictation & $3(2 \%)$ \\
& (3) Power point presentation & $41(27.3 \%)$ \\
& (4) Transparency & $6(4 \%)$ \\
\hline $\begin{array}{l}\text { Ability to use computer and internet } \\
\text { among the study population }\end{array}$ & (1) Difficulty in using computer & $20(13.3 \%)$ \\
& (2) Language problem & $3(2 \%)$ \\
& (3) Both of the above & $2(1.3 \%)$ \\
& (4) Accustomed to use computer \& internet & $125(83.3 \%)$ \\
\hline
\end{tabular}

Most of the study population preferred chalk and board $(66.7 \%)$ and power point presentation (27\%) while dictation and transparency were less preferred method for learning. Most of the study

Table 3 Table showing advantages and disadvantages of E-learning as per study population $(\mathrm{N}=150)$ population were accustomed to use computer \& internet and about $13 \%$ were facing difficulty in using computer.

\begin{tabular}{|c|c|c|c|c|c|}
\hline S.No. & Questions & No & Sometimes & Often & Always \\
\hline 1 & Usage of methods of e-learning by study population & $10(6.7 \%)$ & $88(58.7 \%)$ & $44(29.3 \%)$ & $8(5.3 \%)$ \\
\hline 2 & $\begin{array}{l}\text { Impact of e-learning on increasing the interest towards } \\
\text { topic among the study population }\end{array}$ & $9(6 \%)$ & $58(38.7 \%)$ & $64(42.7 \%)$ & $19(12.7 \%)$ \\
\hline 3 & $\begin{array}{l}\text { Impact of e-learning on building the concept of the study } \\
\text { population }\end{array}$ & $11(7.3 \%)$ & $54(36 \%)$ & $48(32 \%)$ & $37(24.7 \%)$ \\
\hline 4 & Distraction due to add films amongst the study population & $38(25.3 \%)$ & $63(42 \%)$ & $22(14.7 \%)$ & $27(18 \%)$ \\
\hline 5 & $\begin{array}{l}\text { Wastage of time in searching for appropriate study } \\
\text { material amongst the study population }\end{array}$ & $16(10.7 \%)$ & $66(44 \%)$ & $44(29.3 \%)$ & $24(16 \%)$ \\
\hline 6 & $\begin{array}{l}\text { Frequency of eye strain or headache among the study } \\
\text { population }\end{array}$ & $34(22.7 \%)$ & $78(52 \%)$ & $27(18 \%)$ & $11(7.3 \%)$ \\
\hline 7 & Impact of e-learning on increasing the ability to & $14(9.3 \%)$ & $61(40.7 \%)$ & $53(35.3 \%)$ & $22(14.7 \%)$ \\
\hline
\end{tabular}

In this study about $35 \%$ study population were using different methods of e-learning most of the time, $55.4 \%$ study population felt that e-learning helps in increasing their interest and helps in building their concept toward the topic(57\%). About $33 \%$ had experience distraction due to add

Table 4 Table showing view and effects regarding e-learning among study population (150)

\begin{tabular}{|c|c|c|c|}
\hline S .No. & Questions & Options & Frequency \\
\hline 1 & View regarding study material & $\begin{array}{l}\text { (1) Provide latest information } \\
\text { (2) Authenticity is questionable } \\
\text { (3) Both } \\
\text { (4) None }\end{array}$ & $\begin{array}{c}30(20 \%) \\
39(26 \%) \\
74(49.3 \%) \\
7(4.7 \%)\end{array}$ \\
\hline 2 & $\begin{array}{l}\text { Effect of e-learning on the study } \\
\text { population }\end{array}$ & $\begin{array}{l}\text { (1) Increased access to information } \\
\text { (2) Ease in sharing of information } \\
\text { (3) Both } \\
\text { (4) None }\end{array}$ & $\begin{array}{l}32(21.3 \%) \\
25(16.7 \%) \\
89(59.3 \%) \\
4(2.7 \%)\end{array}$ \\
\hline 3 & $\begin{array}{l}\text { Impact of e-learning in improving } \\
\text { performance of the study population }\end{array}$ & $\begin{array}{l}\text { (1) No } \\
\text { (2) To some extent } \\
\text { (3) To a great extent } \\
\text { (4) Can't say }\end{array}$ & $\begin{array}{c}9(6 \%) \\
88(58.7 \%) \\
46(30.7 \%) \\
7(4.7 \%)\end{array}$ \\
\hline 4 & $\begin{array}{l}\text { Reason for difficult access to methods } \\
\text { of e-learning according to the study } \\
\text { population }\end{array}$ & $\begin{array}{l}\text { (1) Non availability of internet } \\
\text { (2) Poor speed of internet } \\
\text { (3) Both } \\
\text { (4) None }\end{array}$ & $\begin{array}{c}19(12.7 \%) \\
50(33.3 \%) \\
72(48 \%) \\
9(6 \%)\end{array}$ \\
\hline 5 & $\begin{array}{l}\text { Perspective of study population about e- } \\
\text { learning }\end{array}$ & $\begin{array}{l}\text { (1) Replace class based learning } \\
\text { (2) Aid to class based learning } \\
\text { (3) Should be integrated with class based learning } \\
\text { (4) None }\end{array}$ & $\begin{array}{l}8(5.3 \%) \\
73(48.7 \%) \\
62(41.3 \%) \\
7(4.7 \%)\end{array}$ \\
\hline
\end{tabular}


In this study $20 \%$ study population felt that elearning methods provides latest information, $26 \%$ believe that authenticity of the information in questionable whereas $50 \%$ agreed with both above. About $60 \%$ had felt that it increased the access to information and ease in sharing of information and about $31 \%$ considered that their performance was improved by e-learning methods. In most of the study population main reason for difficult access to e-learning was non availability of internet and poor speed of internet. Maximum students felt that methods of e-learning either act as an aid to class based learning or should be integrated with class based learning.

Table 5 Table showing relationship between area of schooling and ability to use computer \& internet among the study population (150).

\begin{tabular}{|c|c|c|c|}
\hline \multirow[t]{2}{*}{ Ability to use computer and internet } & \multicolumn{2}{|c|}{ Area of schooling } & \multirow[t]{2}{*}{ Total } \\
\hline & Rural & Urban & \\
\hline Find difficulty & 12 & 8 & 20 \\
\hline Language problem & 2 & 1 & 3 \\
\hline Both of the above & 1 & 1 & 2 \\
\hline Accustomed to use of computer and internet & 35 & 90 & 125 \\
\hline Total & 50 & 100 & 150 \\
\hline
\end{tabular}

Chi-square value $=9.75, P$ value $=0.021$ ( significant $)$

Difference in the area of schooling is significantly related to the ability to use computer and internet. About $90 \%$ of study population with urban background were accustomed to use of computer and internet as compared to only $70 \%$ study population with rural background.

Figure 1 Showing different measures taken by study population to improve their understanding

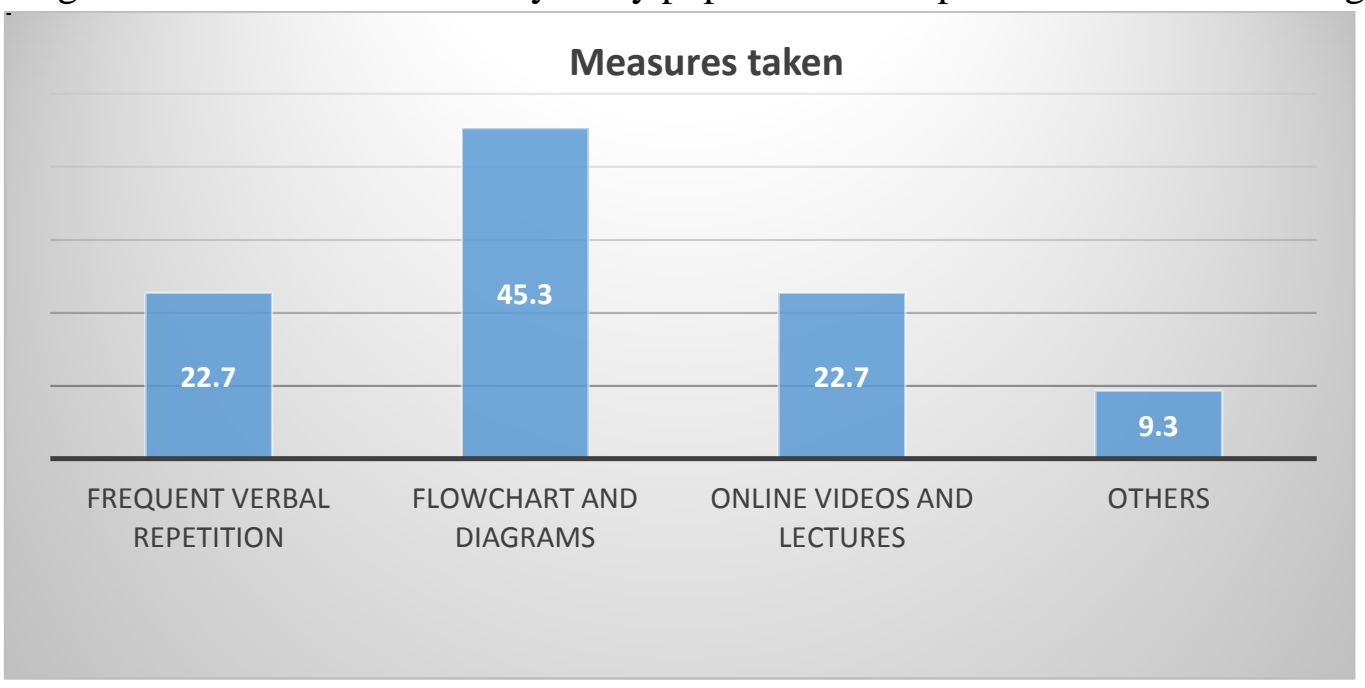

About $45 \%$ study population preferred to make flowcharts and diagrams while $23 \%$ were using online videos and lectures and $23 \%$ had preferred frequent verbal repetition to improve their understanding.

\section{Discussion}

In our study the result for demographic profile by the respondent comprises that $65.3 \%$ are male and $34.7 \%$ are female which are quite similarly with the study done by Azliza Yacoba et al ${ }^{(9)}$ where there were $59.8 \%$ male and $40.2 \%$ were female. In our study awareness towards technology was about $100 \%$ among study population which was similar to the findings of Azliza Yacoba et $\mathrm{al}^{(9)}$ in which the awareness of students towards technology usage is $99.5 \%$. There is only $0.5 \%$ unaware with the technology usage.

In our study we found that many students felt that with use of e-learning methods they performed better and it helps to improve the memorising ability as well as the interest of the students 
towards the subject which is concurrence with the study done by John Fusprow et $\mathrm{al}^{(10)}$ in Nigeria and another study done by Azliza Yacoba et $\mathrm{al}^{(9)}$ in which they found that e-learning system is useful in their study where the percentage of agree shows $46.90 \%$ and strongly agree $32.10 \%$. In our study we found that methods of e learning act as an aid to class based learning or should be integrated with class based learning similarly Theresa Anhimatic et $\mathrm{al}^{(11)}$ in their study done in England concluded that E-learning blended with classical class based learning can provide an educationally superior alternative to traditional learning and they also state that E-learning can't replace class based learning but supplements it while in another study of Arun Gaikwad et al ${ }^{(12)}$, It has been observed that a group of people who oppose to the concept of e-learning saying that it is informative and does not impart the knowledge of the subject. On the other hand, some people oppose classroom learning saying that self learning with the help computers and other ematerial is always better than classroom learning as it does not motivate for self learning. In our study we found that the students who used methods of E-learning for a longer time period had more improvement in their performance which was similar to the findings of Theresa Anhimatic et $\mathrm{al}^{(11)}$ in which duration for which the methods of E-learning have been used was related to the improvement of their performance.

In our study we found that there was difference in the area of schooling with the ability to use computer and internet. About $90 \%$ of study population with urban background were accustomed to use of computer and internet as compared to only $70 \%$ study population with rural background. Similarly Deepshikha Aggarwal ${ }^{(1)}$ in her study state that One of the common disadvantages to e-learning is that some students, especially those for whom English is not their native language, have difficulty communicating and being understood. Another group of students may experience computer or technology anxiety, which may in turn impact their learning and their final grades and Dr.SS Kadam et $\mathrm{al}^{(13)}$ in their study described the Demerits of E-learning was need for suboptimal Time management and Equality of access to learners of all backgrounds and parts of society.

\section{Conclusion}

In this study we concluded that nearly half of the study population feel that e-learning helps in increasing their interest towards the topic. It helps to increased access to information and ease in sharing of information. The main reason for difficult access to e-learning is either non availability or poor speed of internet. Difference in the area of schooling is significantly related to the ability to use computer and internet.

\section{Recommendation}

(1) Measures should be taken at school and college level to provide internet facility to students for learning purpose. It can be done by setting e-libraries. (2) Facilities like internet and computer should also be provided in rural areas.

Funding: No funding sources

Conflict of interest: None declared

Ethical approval: This study was approved by the institutional ethics committee.

\section{References}

1. www.google.com, definition of e-learning, Role of e-Learning in A Developing Country Like India Deepshikha Aggarwal Jagan Institute of Management Studies, Rohini, Delhi - 85. E-Mail: deepshikha.aggarwal@jimsindia.org

2. Rosenberg M. E-Learning: Strategies for Delivering Knowledge in the Digital Age. New York: McGraw-Hill, 2001.

3. Wentling T, Waight C, Gallaher J, La Fleur J, Wang C, Kanfer A. E-Learning: A Review of Literature 2000 〈http://learning.ncsa.uiuc.edu/papers/elearnli t.pdf). Accessed 22 November 2005. University of Illinois National Center for 
Supercomputer Applications, UrbanaChampaign, IL, 2000.

4. Moberg TF, Whitcomb ME. Educational technology to facilitate medical students' learning: background paper 2 of the medical school objectives project. Acad Med. 1999;74:1146-50.

5. Ward JP, Gordon J, Field MJ, Lehmann HP. Communication and information technology in medical education. Lancet. 2001;357: 792-96.

6. Yuen, A., Law, N., \& Wong, K, ICT implementation and school leadership Case studies of ICT integration in teaching and learning. Journal of Educational Administration, 41 (2), 2003,pp158-170.

7. http://www.aamc.org/meded/curric/

8. Tayebinik, M., \& Puteh, M. (2012). Blended learning or e-learning? International Magazine on Advances in Computer Science and Telecommunications (IMACST), 3(1), 103-110.

9. Student Awareness Towards E-Learning In Education Azliza Yacoba*, Aini Zuriyati Abdul Kadirb, O. Zainudinc, A. Zurairahd)

10. John Fuusprow and Aishley Thomson-“ Elearning and its effect on teaching in global age" in college of education, Nigeria(2010).

11. Theresa Anhimatic and William Barrack"Impact of e-learning on class based learning" in university of Wolverhampton, England (2014)

12. E-Learning in India: Wheel of Change Arun Gaikwad1, Vrishali Surndra Randhir2* International Journal of e-Education, eBusiness, e-Management and e-Learning

13. E-Learning For Medical Education In India: A Review Dr. SS Kadam, Dr. P Wani, Dr. S Akhade) Vol 24, Journal of Forensic Medicine, Science and Law (Jan-Jun 2015) A Journal of Medicolegal Association of Maharashtra. 